\title{
Identifying Transcription Regulatory Elements in the Human and Mouse Genomes Using Tissue-specific Gene Expression Profiles
}

\author{
Amitava Karmaker ${ }^{1}$, Kihoon Yoon ${ }^{1}$, Mark Doderer ${ }^{1}$, Russell Kruzelock ${ }^{2}$, Stephen Kwek ${ }^{1^{*}}$ \\ ${ }^{1}$ Department of Computer Science, University of Texas at San Antonio, \\ San Antonio, Texas 78249, USA \\ ${ }^{2}$ The Institute for Drug Development, Cancer Therapy and Research Center, \\ San Antonio, Texas 78245, USA
}

\begin{abstract}
Summary
Revealing the complex interaction between trans- and cis-regulatory elements and identifying these potential binding sites are fundamental problems in understanding gene expression. The progresses in ChIP-chip technology facilitate identifying DNA sequences that are recognized by a specific transcription factor. However, protein-DNA binding is a necessary, but not sufficient, condition for transcription regulation. We need to demonstrate that their gene expression levels are correlated to further confirm regulatory relationship. Here, instead of using a linear correlation coefficient, we used a non-linear function that seems to better capture possible regulatory relationships. By analyzing tissue-specific gene expression profiles of human and mouse, we delineate a list of pairs of transcription factor and gene with highly correlated expression levels, which may have regulatory relationships. Using two closely-related species (human and mouse), we perform comparative genome analysis to cross-validate the quality of our prediction. Our findings are confirmed by matching publicly available TFBS databases (like TRANFAC and ConSite) and by reviewing biological literature. For example, according to our analysis, $80 \%$ and $85.71 \%$ of the targets genes associated with E2F5 and RELB transcription factors have the corresponding known binding sites. We also substantiated our results on some oncogenes with the biomedical literature. Moreover, we performed further analysis on them and found that $B C R$ and $D E K$ may be regulated by some common transcription factors. Similar results for BTG1, FCGR2B and LCK genes were also reported.
\end{abstract}

\section{Introduction}

The completion of the Human Genome Project (HGP) [1-3] signifies not the end of a journey but rather the beginning of an exciting expedition in revealing the secret of the human genome. To be truly benefited from the HGP, we still need to decipher the biological connotation of the sequences; otherwise, these are just some long strings of meaningless letters. The natural next step is to identify the functional elements in the human genome and understand how the genes regulate and interact with each other. While a large number of human genes have been identified, their regulatory mechanism remains mostly unknown even at the transcriptional level[4].

The main mechanism of transcriptional control is to bind transcription factors (TF) to ciselements (TFBS a.k.a. transcription factor binding sites) either upstream or downstream of the regulated gene, scattered all along thousands of base pairs in both intergenic and intragenic regions. In doing so, it either enhances or suppresses gene transcription. To some extent,

\footnotetext{
*Corresponding author,kwek@cs.utsa.edu
} 
trans-elements can be viewed as "keys" needed to unlock the cis-elements which act as "locks". To comprehend gene transcription mechanism, it is not sufficient to know which keys (trans-elements) are needed to lock/unlock a specific gene, but we also need to identify their corresponding locks (cis-elements). Moreover, identification of binding sites serves as a form of validation on the putative trans-elements. If we are able to identify a putative ciselement, say a conserved sequence element, which is over-represented in the genes that we believe to be regulated by a particular transcription factor then it is more plausible that the TF acts as a trans-element.

In silico discovery [5] of binding sites is quite effective for prokaryotes, like Escherichia coli $[6,7]$, where genomes are more compact with many genes being regulated by a single operator that is relatively easy to locate. Similar successes have been reported for simple unicellular eukaryotes, like Saccharomyces cerevisiae [8-10]. The main approach for finding regulatory elements of such simple organisms is to search for overrepresented motifs modeled by known background profiles, such as position weighted matrices (PWMs) [11-17], position specific score matrices (PSSMs) [11, 18, 19], while some use clustering to demarcate cisregulatory modules[20, 21]. For higher multi-cellular eukaryotes, model-based approaches [4, 22-24] that discover patterns among co-expressed genes with respect to regulating transcription factors, have been proposed. The idea behind these techniques involves the proximity of common cis-regulatory modules among the co-expressed genes. Among other common model-based (a.k.a. machine learning) techniques, artificial neural networks [25], greedy algorithm [12], Gibbs Sampling [26], Markov chains [27, 28], Expectation Maximization (EM) algorithm [29] are widely used for eukaryotes. However, it has been reported that these model-prediction techniques are susceptible to high false positive prediction rate and majority of predicted TFBS generated with predictive models (in silico) have no functional role in vivo [14].

To overcome this potential shortcoming, quite a number of algorithms have been presented motivated by "phylogenetic footprinting" [30-33], which is based on searching for similarity in sequences due to selective pressure during evolution,. In fact, phylogenetic footprinting complements the computational approaches, as sequence conservation across lineage reveals segments in genes that might delineate common biological functions. So, to identify regulatory regions, orthologous genes at the sequence level are compared. The underlying hypothesis that inspires phylogeny as a powerful scheme is that sequences related to vital biological functions will be retained under evolutionary selective pressure [34, 35]. It is assumed that the orthologous genes are accountable to the same regulatory mechanisms in different species. Again, phylogenetic footprinting algorithms can detect putative binding sites if it meets two criteria: (1) sequences from organisms with adequate evolutionary distance share the same conserved regions, and (2) TFBS are over-represented in the proximity. Thus novel methods using cross-species genome comparison can significantly improve the overall specificity of predictions $[36,37]$.

Jin et al. [38, 39] analyzed conserved human-mouse orthologous gene pairs to find core promoter elements and Bussemaker et al. [23] addressed the issue of detecting regulatory elements using correlation of expressions. A recent paper by Kim et al. [40] dealt with predicting transcriptional regulatory elements of human promoters using gene expression and promoter analysis data, which compare two pools of genes using z-scores. Our aim here is to find both trans- and cis-elements in the human genome. Further, to ensure better quality of our analysis, we also used mouse tissue-specific gene expression profile and the observation that functional elements tend to be conserved between mouse and human.

As a model organism to compare with, the choice of mouse is obvious [31]. Human and mouse have about 25,000 genes each, of which about eighty percent coincide in DNA sequence abstraction [41]. Along with progress in sequencing and annotations of mouse 
genome [42, 43], genome-scale interspecies comparison techniques have evolved [44], and geneticists have been amazed by the incredible resemblance between human and mouse genomes. In numbers, almost $40 \%$ of total nucleotides show exact matches in global alignments [45], and about $93.2 \%$ of identical nucleotides has been observed in conserved regions [46]. Moreover, the mouse-model is extensively used to study the molecular foundation and therapy of certain diseases, as functionally related genes are preferentially retained in conserved regions [47].

Based on the flavor of the both strategies of phylogenetic footprinting and co-regulated gene expression profiles, in this paper we propose a systematic approach to identify putative transcriptional regulatory elements in both human and mouse genomes. Our algorithm delineates potential TF-gene pairs by analyzing tissue-specific gene expression data of both human and mouse. As a means of validation, we restrict our attention to orthologous TFs and genes that share a common gene symbol between the two species, and validate our findings by comparing against a widely used TFBS profile registry and reviewed literature.

To investigate the efficacy of our technique and utility of our findings, we computed the correlation among TFs and well-recognized oncogenes to analyze their regulation pattern collectively. The objective here is to identify a small collection of common TFs that regulate a group of oncogenes. For instance, we observed that leukemia proto-oncogenes like BCR and $D E K$ may be regulated sharing some common transcription factors. We also have similar results for the genes BTG1, FCGR2B and LCK. These results together with current biomedical literatures serve to corroborate our findings. Additionally, we also clustered the oncogenes based on their correlation with TFs and the results we report here support our earlier analysis.

\section{Methods}

\subsection{Data preprocessing}

As mentioned earlier, we analyzed expression data for both human and mouse to shortlist coexpressed genes with respect to $\mathrm{TF}$. We collected microarray data of normal human tissues[48], which provide us with 26,260 unique genes from 35 different organs. In total, the data set consists of 115 tissue specimens. The tissue samples were obtained from esophagus, lungs, cervix, fallopian tube, breast, ovary, uterus, seminal vesicles, prostate, salivary glands, thyroids, parathyroid, testes, brain, adrenal, heart, stomach, colon, bowel, kidney, liver, lymph, tonsil, spleen, buffy coat, thymus, vagina, skeletal muscle, fallopian tube, uterus and gall bladder. For each experimental tissue sample, Cy5- and Cy3- labeled samples were cohybridized to a cDNA microarray containing 39,711 human cDNA's, representing 26,260 different gene. Expression ratios were globally normalized by mean-centering each gene across all arrays.

Raw microarray expression data for mouse was obtained from [49]. The dataset contains expressions of 41,699 known and predicted mRNAs in 55 tissues. The samples include adrenal, aorta, bladder, bone marrow, brain, brown fat, calvaria cerebellum, colon, cortex, embryo, epididymus, eye, femur, heart, hindbrain, kidney, knee, large intestine, liver, lung, lymph node, mammary gland, mandible, midbrain, olfactory bulb, ovary, pancreas, placenta, prostate, salivary, skeletal muscle, skin, small intestine, snout, spinal cord, spleen, stomach, striatum, teeth, testis, thymus, thyroid, tongue, tongue surface, trachea, trigeminus, uterus etc. As the expression annotations were given for NCBI XM sequences, we had to map those to official NCBI gene[50] annotation. Although the NCBI repository is being updated and adapted, the RefSeq[51] accession number (e.g. XM_213390) may remain unchanged over time. Therefore, direct one-to-one correspondence of gene id and accession number does not 
produce correct gene list. To circumvent this problem, we retrieved the GI (gi) numbers (GenInfo Identifier), which are exclusively assigned to the sequence records. This number also provides a unique identifier to the sequences, and it is not reused across different versions of accession numbers.

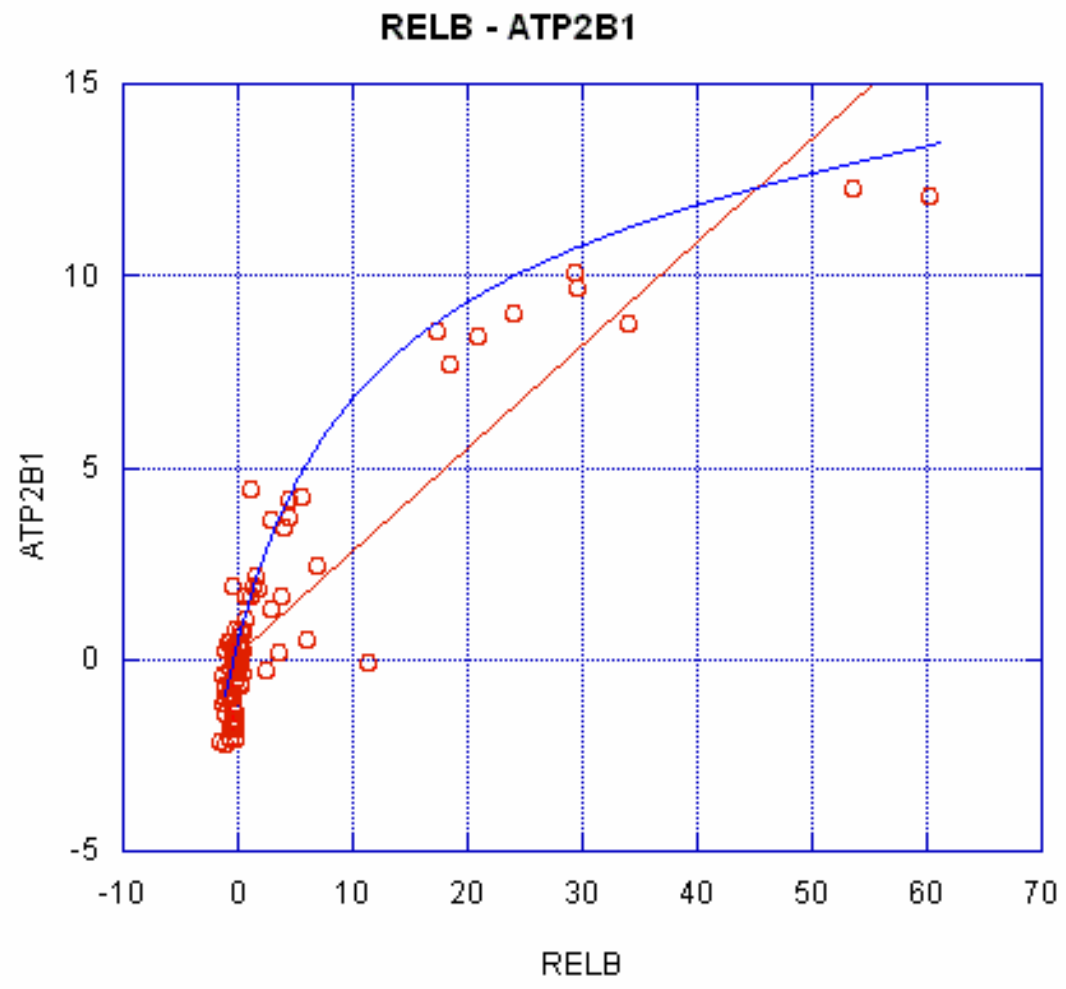

Figure 1: Illustration for TF-gene regulation pattern. Here, the expression data are plotted for TF (RELB) along x-axis, and for gene (ATP2B1) along y-axis. Linear regression (straight line) is unable to capture majority of points, while the non-linear function curve seems to cover most of them.

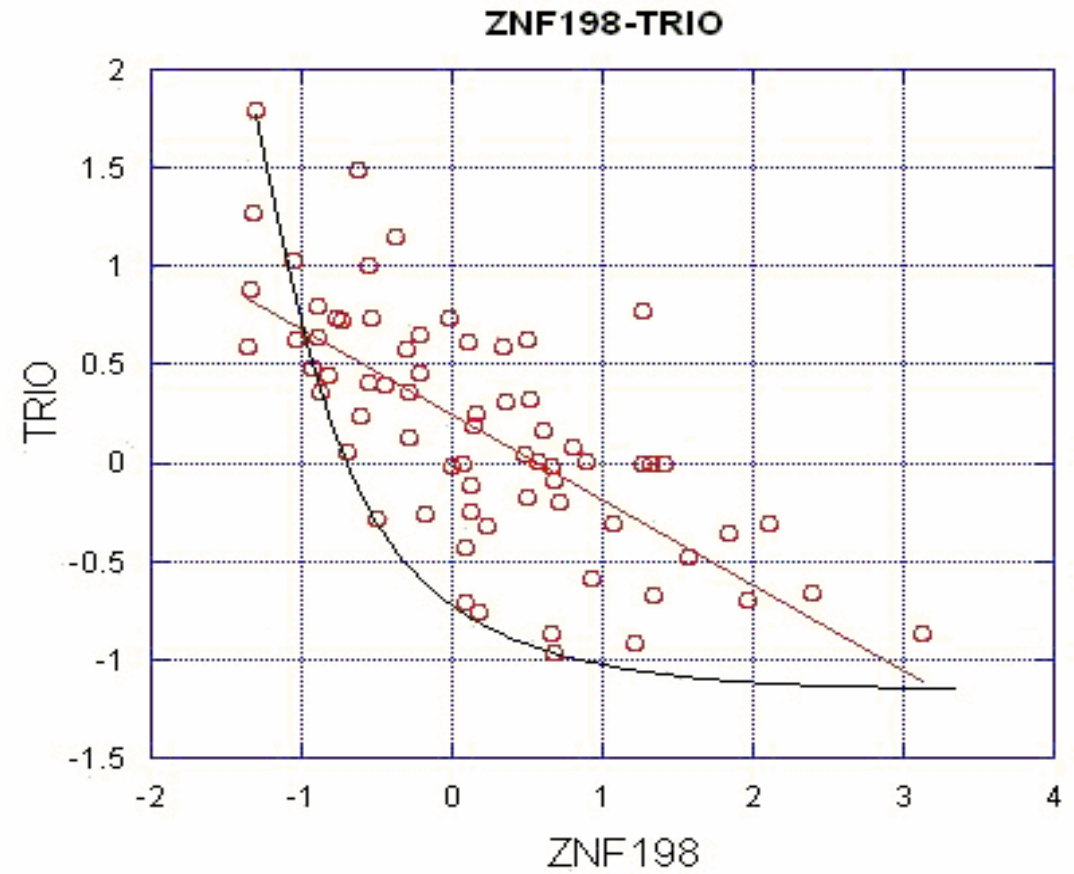

Figure 2: Illustration for negatively correlated TF-gene regulation pattern. 


\subsection{Calculation of correlation coefficient}

If a transcription factor does regulate a gene, according to reported results $[12,24]$ in the literature, it is expected that they are linearly correlated. However, we observed that very often there seems to be a saturation point where the effect on the expression level of the gene diminishes as the level of transcription factor continues to increase and may reach a plateau or even decrease in some cases (see Figure 1). Again, Figure 2 shows the regulation pattern for inversely correlated TF and gene. In these plots, positive numbers represent the up-regulation of genes (or TF), while negative magnitudes for numbers stand for down-regulation of genes. Thus, instead of using simple linear correlation, we measure the correlation using Equation 1 as our regression curve.

$$
y^{\prime}=y e^{\alpha y}, \text { Where } \alpha \text { is exponential constant }
$$

In this equation, $y^{\prime}$ is dependent on the independent variable $y$, which is the original expression level, and it is multiplied by some exponential constant to generate new values (y'). This equation is used commonly in physics to measure half-life to measure radioactive decay. The value of parameter $\alpha$ was set to $0.0,0.25$ and 0.5 in different experimental settings. This correlation coefficient is more general than simple linear correlation coefficient in that by setting $\alpha=0.0$, we end up with the simple linear correlation coefficient.

We calculated Pearson's Correlation Coefficient, of all pairs of gene and TF for both human and mouse datasets using the pre-calculated expression numbers. The values of Pearson's Correlation Coefficient range from -1 to +1 . Any value in positive scale indicates increasing correlationship, with +1 being perfectly linear correlated and negative values denote the case of a negative correlationship. Any value in between in all other cases represents the degree of dependency between the variables (i.e. gene and TF pair). The correlation coefficients indicate how tightly genes are up-regulated and down-regulated with respect to transcription factors.

\subsection{Finding cis-regulatory elements}

To determine the (putative) cis-regulatory elements, we take advantage of the fact that our analysis is from tissue-specific microarray of two mammalian species, human and mouse. Thus, we can identify orthologous genes between the two species that we speculate to be associated with a common $\mathrm{TF}$ and analyze their promoter regions using sequence alignment to determine possible binding site for the TF [34]. For the human genome, we associate a TF as a possible enhancing or repressing regulatory element for a gene if the correlation coefficient is greater than 0.3 or less than -0.3 , respectively. For the mouse genome, we have a more stringent threshold as the correlation coefficients are fairly high. The thresholds for positive and negative correlations are set at 0.4 and -0.4, respectively.

Table 1: List of top ten highly correlated (both positively and negatively) human genes with corresponding transcription factors (here, $\alpha=0.25)$.

\begin{tabular}{|c|c|c|}
\hline Transcription Factor & Gene & $\begin{array}{c}\text { Correlation } \\
\text { Coefficient }\end{array}$ \\
\hline SCAND1 & ASGR1 & 0.9460 \\
\hline NOTCH2 & INSIG1 & 0.9403 \\
\hline ID1 & ITGB1 & 0.9326 \\
\hline TCEB3 & CTGF & 0.9308 \\
\hline STAT4 & S100A8 & 0.9279 \\
\hline ZNF134 & DSTN & 0.9270 \\
\hline
\end{tabular}




\begin{tabular}{|c|c|c|}
\hline RELB & ATP2B1 & 0.9268 \\
\hline RELB & PSMB9 & 0.9190 \\
\hline RBPSUH & SSR4 & 0.9173 \\
\hline SCAND1 & F2 & 0.9151 \\
\hline ZNF198 & TRIO & -0.6928 \\
\hline PPARBP & CENPB & -0.6882 \\
\hline GABPA & C22orf5 & -0.6831 \\
\hline HCLS1 & C4A & -0.6803 \\
\hline ZNF228 & EHD1 & -0.6800 \\
\hline TEAD3 & ARFGEF2 & -0.6705 \\
\hline PPARBP & EPN1 & -0.6695 \\
\hline HCLS1 & C4A & -0.6683 \\
\hline PPARBP & BCR & -0.6650 \\
\hline GABPA & NCOR2 & -0.6645 \\
\hline
\end{tabular}

Transcriptional regulatory elements are found either upstream or downstream of genes, scattered all along thousands of bps in both intergenic and intragenic regions. However, most TFBS predictors tend to focus in the proximal promoter region [52] because the difficulty of TFBS prediction tends to increase with the size of the region of interest. Besides, increasing the region of interest upstream of the transcription start site to more than a few thousand base pairs increases the chances of falsely identifying common repeat elements. Thus, we focus on the core promoter regions from $500 \mathrm{bps}$ upstream to $200 \mathrm{bps}$ downstream $(-500$ to +200 , total 700 bps).

To ensure that our putative TF binding sites are of high quality, we validated them with TRANSFAC database [24, 53, 54]. TRANSFAC contains the largest repository for experimentally derived TFBS. We also performed further validations of our putative sites using P-Match [55]-public and ConSite [56], which combines pattern matching and weight matrix approaches thus providing higher accuracy of recognition than each of the methods alone. To reduce false-positive validation using P-match, we chose "high quality vertebrate matrices only" as our default option. We obtained the report for all pre-selected genes, setting cut-off selection for matrices to minimize (1) false-positive, (2) false-negative, and (3) the sum of both error rates. Moreover, ConSite [56] is a user-friendly, web-based tool for finding cis-regulatory elements in genomic sequences using high-quality transcription factor models and cross-species comparison filtering.

\subsection{Clustering the oncogenes}

In order to explore the collective interactions among $\mathrm{TF}$ and oncogenes, we clustered the oncogenes with respect to regulating TFs. We constructed an interaction matrix, M, where each entry is either one (1) or zero (0) individually based on the correlation coefficients of the respective TF-gene pairs. For each possible pair of genes, if the number of one's along the rows exceeds a cut-off, we assign them in the same cluster. These pairs of genes will then be used as 'seeds' to grow the cluster in a greedy fashion, where new gene is added to the cluster if its putative TFBS are found to contain many of the putative TFBS of the genes already in the cluster. In each cluster, the correlations between TF and oncogenes are analyzed as a group to capture their differential regulation patterns. 


\section{$3 \quad$ Results and Discussion}

\subsection{Correlated genes and transcription factors}

Using Pearson's Correlation Coefficient (see Methods section), we constructed a list of TFgene pairs, either correlated or inversely correlated to each other. Table 1 and Table 2 show the top ten most positively and negatively correlated genes and transcription factors for human $(\alpha=0.25)$ and mouse $(\alpha=0.5)$ in order. The complete list of correlated pairs can be obtained from our website [57].

We find that many of the TF-gene pairs fit the non-linear function better, especially for the human genome. Using a threshold of +0.8 on the correlation coefficients, we find that the non-linear function seems to better depict the possible relationship between the TFs and genes, especially for the human genome. In our dataset for human, we have $1,114,432$ possible TF-gene pairs. Of them, the number of correlated pairs are 171 (topmost $0.015 \%$ ), $372(0.033 \%)$ and $253(0.023 \%)$ for $\alpha=0.0$ (linear), $\alpha=0.25$ and $\alpha=0.50$ respectively. Further, we observed that the correlation coefficients of most pairs are greater when $\alpha=0.25$ as opposed to $\alpha=0.0$. However, the effect on the mouse genome is not as dramatic, which is partly, we believe, due to the already higher linear correlation coefficient. Out of 4,52,076 possible TF-gene pairs, we found 2,448 (topmost $0.541 \%), 3,150(0.70 \%)$ and 3,472 $(0.77 \%)$ correlated TF-gene pairs for corresponding $\alpha=0.0$ (linear), $\alpha=0.25$ and $\alpha=0.50$ above +0.8 correlation coefficient. Therefore, our results concentrate on the correlated TF-gene pairs for human at $\alpha=0.25$, and for mouse $\alpha=0.5$. One of the novelties of our approach is that the technique can be scaled up by associating more genomes in the lineage, provided cis-elements are spatially conserved.

In the results for human expression data, we found that SCAND1 (SCAN domain containing 1) and RELB (v-rel reticuloendotheliosis viral oncogene homolog B) appear more often than others. SCAND1 is positively correlated with both ASGR1 (Asialoglycoprotein receptor 1) and F2 (Coagulation factor II (thrombin)), while RELB shows the same pattern with ATP2B1 (ATPase, $\mathrm{Ca}++$ transporting, plasma membrane 1) and PSMB9 (Proteasome subunit, beta type, 9). In fact, the interactions between RELB and PSMB9 are reported in the literature [58]. As shown in Figure 1, the regulation pattern among TFs and genes tends to better fit the decay function curve than simple linear line, which characterizes our assumption regarding TF-gene interaction model. In fact, we observed that the correlation coefficient of most TF-gene pairs tend to be higher for the non-linear function regressor than linear regressor.

Table 2: List of top ten highly correlated (both positively and negatively) mouse genes with corresponding transcription factors (here, $\alpha=0.5$ ).

\begin{tabular}{|c|c|c|}
\hline Transcription Factor & Gene & $\begin{array}{c}\text { Correlation } \\
\text { Coefficient }\end{array}$ \\
\hline LEF1 & EPM2A & 0.9946 \\
\hline HOXB1 & $1700014 N 06 R I K$ & 0.9874 \\
\hline FOXE1 & DFNA5H & 0.9825 \\
\hline RFX1 & MESP1 & 0.9816 \\
\hline FOXE1 & $2610207 F 23 R I K$ & 0.9799 \\
\hline FOXE1 & $5730403 I 07 R I K$ & 0.9778 \\
\hline CREB1 & $2810025 M 15 R I K$ & 0.9750 \\
\hline E4F1 & $4930424 G 05 R I K$ & 0.9733 \\
\hline ZIC1 & GTF2E2 & 0.9720 \\
\hline ACE & $1700027 M 21 R I K$ & 0.9718 \\
\hline$L E F 1$ & REN & -0.9545 \\
\hline$M B P$ & $5930416 I 19 R I K$ & -0.9501 \\
\hline & \multicolumn{2}{|}{} \\
\hline
\end{tabular}




\begin{tabular}{|c|c|c|}
\hline FOXM1 & LOC238771 & -0.9494 \\
\hline FOXD2 & 8030423J24RIK & -0.9442 \\
\hline AP1M1 & P2RY2 & -0.9386 \\
\hline MBP & 2700099C18RIK & -0.9354 \\
\hline ZIC2 & CLDN4 & -0.9345 \\
\hline SIN3B & KCNJ11 & -0.9339 \\
\hline HOXB1 & $9030420 J 04 R I K$ & -0.9297 \\
\hline PITX1 & MCF2 & -0.9167 \\
\hline
\end{tabular}

However, in the cases of anti-correlations, the coefficient numbers of TF-gene pairs are relatively low, which is possibly due to intrinsic experimental intricacy in measuring negativity in the gene expressions. Among the top short-listed pairs, PPARBP (PPAR binding protein), GABPA (GA binding protein transcription factor, alpha subunit $60 \mathrm{kDa}$ ) and HCLS1 (Hematopoietic cell-specific Lyn substrate 1) showed up more frequently with corresponding down-regulated genes.

Our analysis of mouse expression data revealed that there are surprisingly strong correlations among genes in both directions, with 3,684 pairs having coefficient greater than 0.8 or below -0.8 as opposed to 372 in human. We believe that this is probably an artifact of the data. FOXE1 (Forkhead box E1) showed up most often in the positively correlated pairs, while MBP (Myelin basic protein) is the most frequently occurring in the negative list. Some TFs seemed to enhance the expression level of some genes while suppressing others. For example, LEF1 (Lymphoid enhancer-binding factor 1) and HOXB1 (Homeo box B1) are included in both positive and negative list.

Table 3: The list of identified binding sites for four TFs. The consensus sequence logo plots for available PWM's in TRANSFAC are shown. Results were validated using both TRANSFAC and ConSite.

\begin{tabular}{|c|c|c|c|c|}
\hline \multicolumn{5}{|c|}{ For TF E2F5 } \\
\hline Genes & Factor Name & $\begin{array}{l}\text { Position in } \\
\text { Human } \\
\text { sequence } \\
\text { (strand) }\end{array}$ & $\begin{array}{c}\text { Position in Mouse } \\
\text { sequence } \\
\text { (strand) }\end{array}$ & Consensus sequence \\
\hline EZH2 & $\begin{array}{c}\text { TRANSFAC } \\
\text { (P-Match): E2F } \\
\text { ConSite : E2F }\end{array}$ & $533(+)$ & $494(+)$ & TTTGGcge \\
\hline$R P A 2$ & $\begin{array}{c}\text { TRANSFAC } \\
\text { (P-Match): E2F } \\
\text { ConSite : E2F }\end{array}$ & $331(+)$ & $158(+)$ & TTTGGege \\
\hline TYMS & $\begin{array}{c}\text { TRANSFAC } \\
\text { (P-Match): E2F } \\
\text { ConSite : E2F }\end{array}$ & $464(-)$ & $468(-)$ & gcgGGAAA \\
\hline CRTAP & & & No Hits & \\
\hline
\end{tabular}




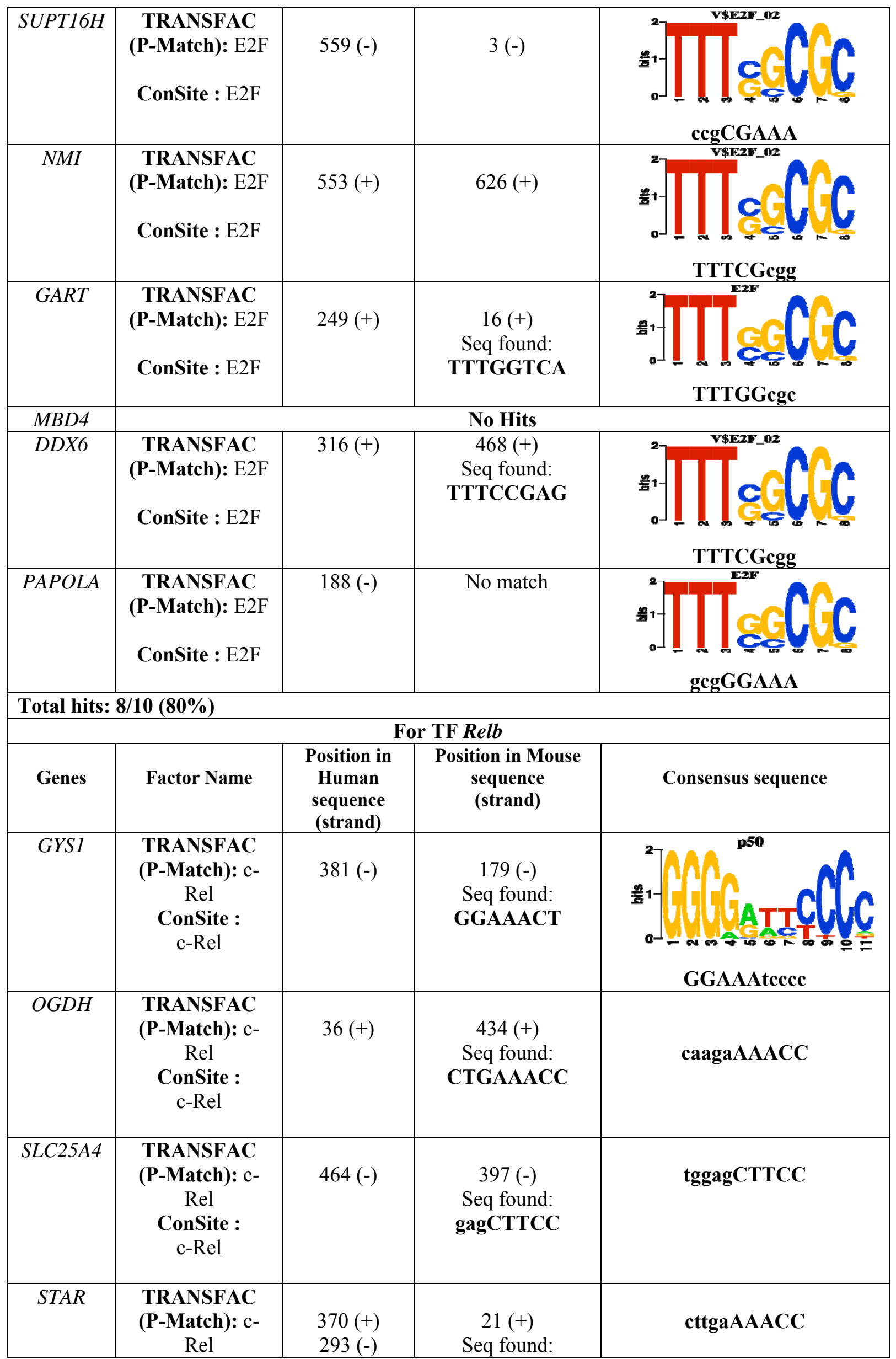




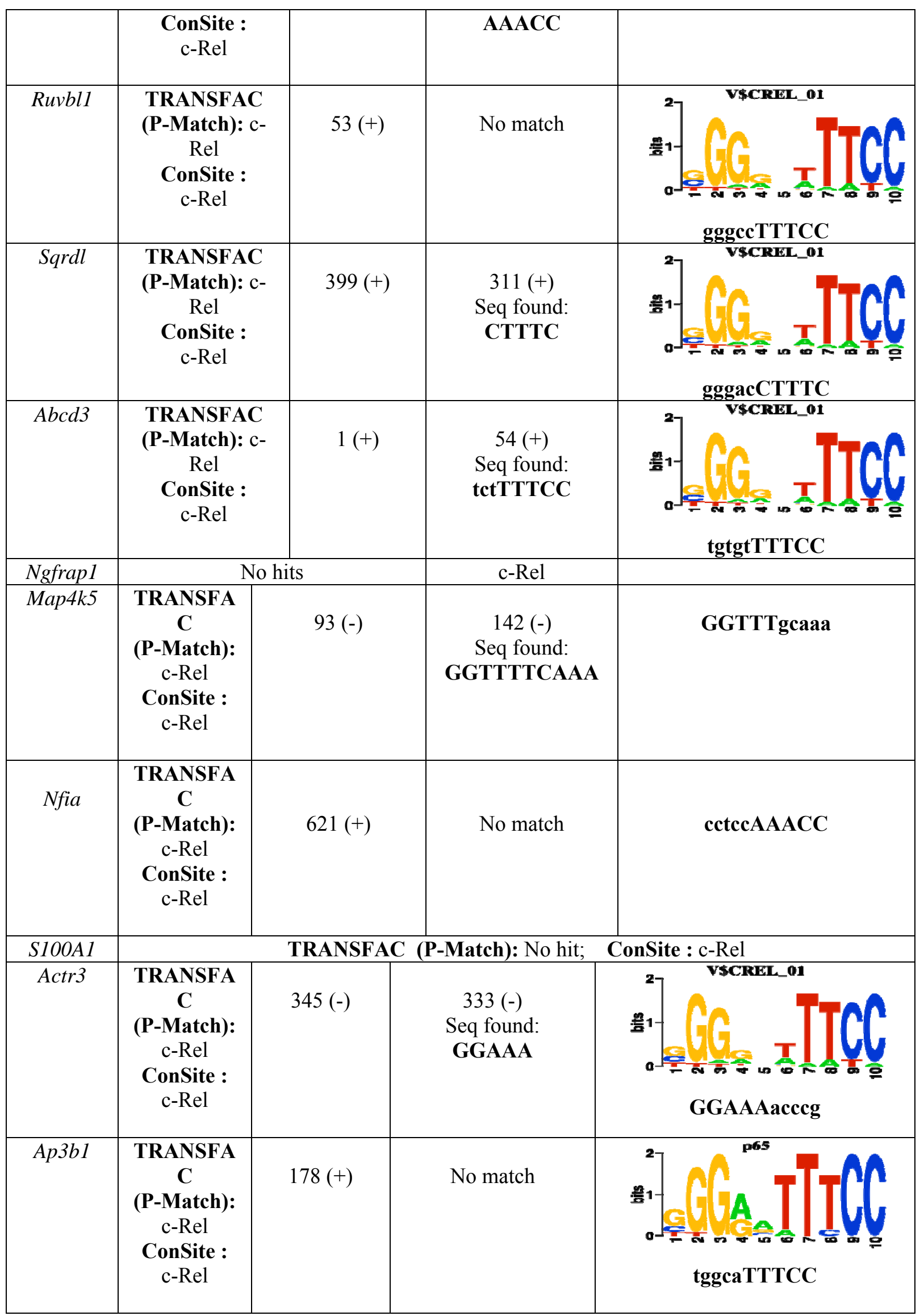




\begin{tabular}{|c|c|c|c|c|}
\hline Btg1 & $\begin{array}{l}\text { TRANSFA } \\
\text { C } \\
\text { (P-Match): } \\
\text { c-Rel } \\
\text { ConSite : } \\
\text { c-Rel }\end{array}$ & $203(+)$ & $187(+)$ & 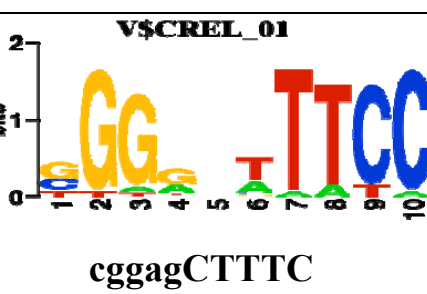 \\
\hline \multicolumn{5}{|c|}{ Total hits: $12 / 14(85.71 \%)$} \\
\hline \multicolumn{5}{|c|}{ For TF Sp3 } \\
\hline Genes & Factor Name & $\begin{array}{l}\text { Position in } \\
\text { Human } \\
\text { sequence } \\
\text { (strand) } \\
\end{array}$ & $\begin{array}{l}\text { Position in Mouse } \\
\text { sequence } \\
\text { (strand) }\end{array}$ & Consensus sequence \\
\hline CLPTM1 & $\begin{array}{l}\text { TRANSFAC } \\
\text { (P-Match): } \\
\text { YY1 } \\
\text { ConSite : } \\
\text { Yin-yang }\end{array}$ & $506(-)$ & $\begin{array}{c}507(-) \\
\text { Seq found: } \\
\text { ggaagATGGCggcgg }\end{array}$ & gagcgggaagATGGCggcgg \\
\hline PPARBP & $\begin{array}{l}\text { TRANSFAC } \\
\text { (P-Match): } \\
\text { YY1 } \\
\text { ConSite : } \\
\text { No Match } \\
\end{array}$ & $497(-)$ & $485(-)$ & gttggggaagATGGCggegg \\
\hline ARPC2 & $\begin{array}{c}\text { TRANSFAC } \\
\text { (P-Match): } \\
\text { YY1 } \\
\text { ConSite : } \\
\text { No Match } \\
\end{array}$ & $432(-)$ & $443(-)$ & gaagcggaaATGGCgccgc \\
\hline AP1M1 & \multirow{2}{*}{\multicolumn{4}{|c|}{$\begin{array}{ll}\text { TRANSFAC (P-Match): No hit; } & \text { ConSite : Yin-yang } \\
\text { TRANSFAC (P-Match): No hit; } & \text { ConSite : Yin-yang }\end{array}$}} \\
\hline CIT & & & & \\
\hline$G A B P A$ & $\begin{array}{l}\text { TRANSFAC } \\
\text { (P-Match): } \\
\text { YY1 } \\
\text { ConSite : } \\
\text { No Match }\end{array}$ & $\begin{array}{l}49(+) \\
212(+)\end{array}$ & $\begin{array}{c}430(+) \\
\text { Seq found: } \\
\text { ctccGCCATcttt }\end{array}$ & $\begin{array}{l}{ }_{2}^{2} \\
\text { tacccGCCATcgeaatgcat } \\
\text { cetccGCCATetttettcg }\end{array}$ \\
\hline \multicolumn{5}{|c|}{ Total hits: $4 / 6(66.67 \%)$} \\
\hline \multicolumn{5}{|c|}{ For TF STAT4 } \\
\hline Genes & Factor Name & $\begin{array}{l}\text { Position in } \\
\text { Human } \\
\text { sequence } \\
\text { (strand) } \\
\end{array}$ & $\begin{array}{c}\text { Position in Mouse } \\
\text { sequence } \\
\text { (strand) }\end{array}$ & Consensus sequence \\
\hline ARPC2 & \multicolumn{4}{|c|}{ No hits } \\
\hline TMSB10 & $\begin{array}{c}\text { TRANSFAC } \\
\text { (P-Match): } \\
\text { STATx } \\
\text { ConSite : } \\
\text { STATx }\end{array}$ & $235(+)$ & $\begin{array}{l}213(+) \\
\text { Seq found: } \\
\text { TTCCCg }\end{array}$ & TTCCCggaa \\
\hline
\end{tabular}

We screened out common genes that are co-expressed with these TFs. In order to quantify the conservation of regulatory elements along these gene sequences, the core promoter regions (see Methods) were fed to P-Match [55] using all three available options for handling false discoveries. Basically, the output with option "minimizing false negative" considers merely minimal number of base pairs match and calls it a hit. Thus it improves its recall numbers 
(maximize loose-bound relevance at the cost of precision), with a huge list of cis-element candidates. We expect the false-positive rate to be extremely high for the predictions to be meaningful. Therefore, we did not discard this option. Among the other options, "minimize false positive" tries to find exact $(\sim 100 \%)$ PWM match and accounts for the most precise TF hits. The other option "minimize sum of both error rates" seems to take advantage from the best of both worlds (keeping balance on both recall and precision) and evens out high false discovery rates. To ensure better quality of our analysis, we considered only the option "minimize false positive", which maximizes the precision values without compromising too much with recall values. We summarize the sample results (precision $>=50 \%$ ) for both human and mouse genomes in Table 3. The results for consulting ConSite are furnished as well. The consensus sequences (Logo-plots) for respective TFBS were extracted from TFMExplorer [17].

Among eight TFs, our prediction performances for four TFs are encouraging while there is no highly correlated human pair showed up for the other four TFs. For instance, out of the 10 human genes that are associated with E2F5 (E2F transcription factor 5), a member of E2F TF family, 8 genes $(80 \%$ hit rate) carry the supposed binding sites. Comparing the sequence patterns of binding sites, we can say that almost all of them share the consensus 'TTTSSCGC' where S could be a C or G. Out of these 8 human genes that are hit, 7 of the mouse orthologs also have the consensus sequence 'TTTSSCGC' in the promoter region.

As per validation, we reviewed biological literature and found that there is a strong association between E2F5 and EZH2 (enhancer of zeste homolog 2), which appears in our result for binding site predictions. The E2F transcription factors, considered to be oncogenes [59], are key regulators of cell cycle progression [60], apoptosis and DNA damage response [61]. Loss of E2F functionality results in acute developmental effects [62]. It is also evidenced that $p R B-E 2 F$ pathway (The retinoblastoma protein-E2F) strongly regulates the expressions of Polycomb group genes (PcG), one of which is EZH2 [63, 64]. Again, EZH2 is downstream of the $p R B-E 2 F$ pathway and it is up-regulated during the cell proliferation and down-regulated during the cell differentiation phases [65].

Likewise, for the 14 human genes correlated with TF RELB, we have found 12 genes have the consensus sequence for RELB binding which achieve a hit rate of $(85.71 \%)$. Among these 12 human genes, the mouse orthologs of 10 genes also contain some consensus sequence for RELB binding. Here, we found "TTTCC" as sense (+), or "GGAAA" as anti-sense (-) complementary, to be common motif with a number of out of pattern nucleotides around. Similarly, the precision rate for sp3 (Sp3 transcription factor) is $66.67 \%$ (4 hits out of 6 genes) and for STAT4 (signal transducer and activator of transcription 4) is 50\% (1 hit from 2 genes). For sp3, listed genes have cis-elements containing motif "GCCAT" as sense $(+)$, or "ATGGC" as anti-sense (-) counterpart. We believe that the hit rates for the rest are trivial due to the lack of sufficient correlated genes showing up.

\subsection{Analyses of oncogenes}

We selected a number of proto-oncogenes that are linked to various types of leukemia (AML, ALL, CML etc.) and breast cancer to illustrate our analyses. As discussed below, some correlated TF-gene pairs have been shown to bear regulatory relationship (Table 4 and Table 5). Moreover, some prospective candidates in our results actually comply with supporting biological literature reviews. 


\subsubsection{Leukemia genes}

The BCR (Breakpoint cluster region) contains the Chromosome 22 breakpoint for the translocation that produces Philadelphia Chromosome [66], which is very often found in patients with CML (Chronic Myelogenous Leukemia). The translocation occurs between BCR (in Chromosome 22) and ABL ( $v$-abl Abelson murine leukemia viral oncogene homolog in Chromosome 9q34), and this reciprocal translocation creates a tyrosine kinase, which is self-activated. Eventually this complex speeds up cell division, inhibits DNA repair, and causes genomic instability and blast effect in CML. Our analysis shows that BCR is upregulated with NR2F6 and PCOLN3, which complements previous studies [67,68]. Our other candidates are CENPB (Centromere protein B) and NCOR2 (Nuclear receptor co-repressor 2) as positively correlated transcription factors and SP3 (Sp3 transcription factor) as negatively correlated transcription factors.

One of the well-recognized oncogenes for AML (Acute Myelogenous Leukemia) is $M L L$ (myeloid/lymphoid or mixed-lineage leukemia) [69-72]. In our analysis, we found MDM2 (transformed 3T3 cell double minute 2, p53 binding protein), which is a potential target of tumor suppressor protein p53, to be up-regulated with $M L L$. Over-expression of MDM2 may cause excessive inactivation of tumor protein $\mathrm{p} 53$, deteriorating its tumor suppressor function $[73,74]$.

The DEK (DEK oncogene) gene produces a fusion with the CAN protein in a subtype of AML patients [75]. We found HMGB1 (high-mobility group box 1) in our analysis, and it was also reported in the literature as a gene which controls the binding behavior of DEK [76]. Another transcription factor correlated with DEK is $s p 3$ (Sp3 transcription factor) [77].

We also furnished correlated transcription factors for LMO2 (LIM domain only 2), ETV6 (ets variant gene 6), RUNX1 (runt-related transcription factor 1, also called AML1), BTG1 (B-cell translocation gene 1, anti-proliferative) FCGR2B (Fc fragment of $\mathrm{IgG}$, low affinity IIb, receptor, Loc. 1q23), LCK (lymphocyte-specific protein tyrosine kinase, Loc. 1p34.3), which are relevant to leukemia.

Table 4: The list of transcription factors highly correlated to leukemia genes

\begin{tabular}{|c|c|c|c|c|c|}
\hline Gene & $\begin{array}{c}\text { Transcription } \\
\text { Factor }\end{array}$ & $\begin{array}{c}\text { Correlation } \\
\text { Coefficient }\end{array}$ & Gene & $\begin{array}{c}\text { Transcription } \\
\text { Factor }\end{array}$ & $\begin{array}{c}\text { Correlation } \\
\text { Coefficient }\end{array}$ \\
\hline & ZMIZ2 & 0.6532 & & PLEK & 0.8295 \\
\hline & DPP7 & 0.6446 & & SP110 & 0.7726 \\
\hline & EPN1 & 0.5957 & & DOCK2 & 0.7502 \\
\hline & GRINA & 0.5837 & & TMSB4Y & 0.7468 \\
\hline \multirow[t]{10}{*}{$B C R$} & HMOX2 & 0.5641 & BTG1 & CD53 & 0.7301 \\
\hline & $G A B P A$ & -0.6634 & & GCSH & -0.5434 \\
\hline & PPARBP & -0.6360 & & BMPR1A & -0.5015 \\
\hline & TFAM & -0.6298 & & LRP6 & -0.4736 \\
\hline & МАРКВIPЗ & -0.6247 & & PFN2 & -0.4682 \\
\hline & STAG2 & -0.6236 & & ZDHHC7 & -0.4587 \\
\hline & ADAMTS1 & 0.6352 & & $R A C 2$ & 0.9286 \\
\hline & YWHAZ & 0.6003 & & TRB@ & 0.9107 \\
\hline & IFI16 & 0.5976 & & LIMD2 & 0.9086 \\
\hline & KLF4 & 0.5855 & & $C D 3 D$ & 0.8960 \\
\hline \multirow[t]{5}{*}{$M Y C$} & TUBA3 & 0.5813 & $L C K$ & DOCK2 & 0.8875 \\
\hline & MYO10 & -0.5300 & & NCKAP1 & -0.6768 \\
\hline & GCSH & -0.5190 & & LRP6 & -0.6414 \\
\hline & XPO4 & -0.5034 & & RBM9 & -0.6216 \\
\hline & DDAH1 & -0.4945 & & YAP1 & -0.6174 \\
\hline
\end{tabular}




\begin{tabular}{|c|c|c|c|c|c|}
\hline & MAPRE3 & -0.4925 & & BMPR1A & -0.6041 \\
\hline & HMGB1 & 0.7934 & & FCGR2C & 0.8553 \\
\hline & STAG2 & 0.7594 & & FCER1G & 0.8087 \\
\hline & GDI2 & 0.7302 & & AIF1 & 0.7920 \\
\hline & PSMA4 & 0.7113 & & HCLS1 & 0.7877 \\
\hline \multirow[t]{10}{*}{$D E K$} & PPARBP & 0.7073 & FCGR2B & HEM1 & 0.7851 \\
\hline & WWP2 & -0.5237 & & TOM1L1 & -0.5286 \\
\hline & ATP6V0A1 & -0.5220 & & MTX2 & -0.4815 \\
\hline & $Q D P R$ & -0.5002 & & PFN2 & -0.4796 \\
\hline & EPN1 & -0.4984 & & HDLBP & -0.4759 \\
\hline & GRINA & -0.4897 & & H1F0 & -0.4735 \\
\hline & DNCH1 & 0.6081 & & $\mathrm{SSH} 2$ & 0.5702 \\
\hline & AKAP11 & 0.5910 & & MSL3L1 & 0.5087 \\
\hline & MPHOSPH1 & 0.5363 & & MAP4K4 & 0.5024 \\
\hline & DNCH1 & 0.5282 & & BRD4 & 0.4790 \\
\hline \multirow[t]{10}{*}{$M L L$} & TERF2 & 0.4534 & RUNX1 & GMFG & 0.4715 \\
\hline & $P R D X 6$ & -0.4987 & & CRYL1 & -0.5235 \\
\hline & KIAA0152 & -0.4449 & & FLJ20315 & -0.4564 \\
\hline & IL1R1 & -0.4410 & & GJA7 & -0.4508 \\
\hline & TM9SF1 & -0.4235 & & AIG1 & -0.4493 \\
\hline & MID1 & -0.4225 & & CRYZ & -0.4377 \\
\hline & $P T H$ & 0.5959 & & $I N P P 4 B$ & 0.6494 \\
\hline & GATA3 & 0.5737 & & МАРЗК & 0.6462 \\
\hline & $S Y K$ & 0.5693 & & $\mathrm{CHDH}$ & 0.6392 \\
\hline & $P V A L B$ & 0.5657 & & SWAP70 & 0.6307 \\
\hline \multirow[t]{6}{*}{ ETV6 } & $P T N$ & 0.5468 & LMO2 & PTTG1 & 0.6187 \\
\hline & KIAA0934 & -0.4292 & & NBEA & -0.4997 \\
\hline & PMP22 & -0.4246 & & CDC42BPA & -0.4722 \\
\hline & FBN1 & -0.4151 & & MXI1 & -0.4624 \\
\hline & TCF8 & -0.4138 & & $X K$ & -0.4319 \\
\hline & NT5E & -0.4064 & & EXTL2 & -0.4251 \\
\hline
\end{tabular}

Our analyses on oncogenes provide some supporting evidence for the correlations between transcription factors and corresponding genes. Most often, the findings are consistent with what we found in biological literature surveys. Also we find a number of significant candidates that may be quite relevant to cancer studies. For example, NR2F6, which is a nuclear receptor, is positively correlated with breast cancer gene (ErbB2) and one of the leukemia genes $(B C R)$, while it is inversely correlated with other leukemia gene (DEK). Collectively, we may analyze the inter-relationships among leukemia genes and correlated transcription factors (see Table 6). Similarly, we discovered identical expression pattern among BTG1, FCGR2B and LCK genes (see Table 7). In fact, FCGR2B and LCK show up in the B-Cell Receptor Signaling Pathway and the T-Cell Receptor Signaling Pathway respectively, which seems to be the reason for this concurrence.

Table 5: The list of transcription factors correlated to breast cancer genes

\begin{tabular}{|l|c|c|}
\hline Gene & Transcription Factor & Correlation Coefficient \\
\hline \multirow{4}{*}{} & FOXM1 & 0.4913 \\
\cline { 2 - 3 } & HMGA1 & 0.5195 \\
\cline { 2 - 3 } & HHEX & 0.4388 \\
\cline { 2 - 3 } & MCM5 & 0.4048 \\
\cline { 2 - 3 } & GMEB1 & 0.395 \\
\hline
\end{tabular}




\begin{tabular}{|c|c|c|}
\hline BRCA1 & PTTG1 & 0.3839 \\
\hline \multirow{4}{*}{} & E2F1 & 0.3816 \\
\cline { 2 - 3 } & NFIB & -0.4069 \\
\cline { 2 - 3 } & FOSB & -0.2364 \\
\cline { 2 - 3 } & EGR1 & -0.2075 \\
\hline \multirow{5}{*}{} & TBX3 & -0.1882 \\
\cline { 2 - 3 } & LPIN1 & 0.7520 \\
\cline { 2 - 3 } & SPINT1 & 0.6570 \\
\cline { 2 - 3 } & MKNK2 & 0.6365 \\
\cline { 2 - 3 } & DDR1 & 0.6153 \\
\cline { 2 - 3 } & NR2F6 & 0.4288 \\
\hline ErbB2 & MEF2C & -0.5445 \\
\hline & NIN & -0.52263 \\
\cline { 2 - 3 } & MBNL1 & -0.52012 \\
\cline { 2 - 3 } & SSBP2 & -0.51904 \\
\cline { 2 - 3 } & ZFP91 & -0.4626 \\
\hline
\end{tabular}

\subsubsection{Breast cancer genes}

Unlike leukemia oncogenes, we applied our analysis on two well-known breast cancer genes, namely BRCA1 and ErbB2. Because of small number of genes, clustering is not feasible to discover the interactions. However, we found some associations among these genes, which are backed by literature.

Certain mutations of BRCA1 (Breast Cancer 1, early onset) cause approximately $40 \%$ of inherited breast cancers and more than $80 \%$ of inherited breast and ovarian cancers [78-89]. Our analysis reveals that FOXM1, E2F1, PTTG1, HMGA1, GMEB1, MCM5 and HHEX transaction factor genes are positively correlated to the expression of BRCA1, while expressions of NFIB, EGR1, FOSB, and TBX3 appear to be inversely correlated to that of BRCA1.

Table 6: Association analysis of $B C R$, and $D E K$ with transcription factors in terms of regulation pattern

\begin{tabular}{|c|c|c|}
\hline TF & BCR & DEK \\
\hline NR2F6 & +0.4302 & -0.3505 \\
\hline NCOR2 & +0.4343 & -0.3916 \\
\hline ZNF74 & +0.4504 & -0.2813 \\
\hline PCOLN3 & +0.3442 & -0.2912 \\
\hline NR1D1 & +0.3491 & -0.2866 \\
\hline HMX1 & +0.4477 & -0.4396 \\
\hline HMGB1 & -0.5228 & +0.7934 \\
\hline ATF1 & -0.5145 & +0.5373 \\
\hline SP3 & -0.5664 & +0.6177 \\
\hline TFAM & -0.6298 & +0.6165 \\
\hline GABPA & -0.6634 & +0.6907 \\
\hline NPM1 & -0.6390 & +0.6731 \\
\hline ELF1 & -0.4434 & +0.6473 \\
\hline
\end{tabular}

FOXM1 (Forkhead box M1) has been found to be responsible for epithelial ovarian tumors correlated with malignancy [90] and it is over-expressed in transcriptional regulations. There is much evidence that E2F1 (E2F transcription factor 1) is related to control of BRCA1. 
Hennighausen [91] simulated the mouse model of breast cancer and established the presence of E2F1 in cancer-causing. Again, the E2F family plays a crucial role in the control of cell cycle and action of tumor suppressor proteins and is also a target of the transforming proteins of small DNA tumor viruses. So, E2F-responsive promoters appear to be more active in tumor cells relative to normal cells. Recently, pharmacogenomics studies showed that murinederived anticancer agents, namely YondelisTM (Trabectedin, ET-743) [92], target markers like PTTG1 (pituitary tumor-transforming 1) and HHEX (Homeobox, hematopoietically expressed). Baldassarre et. al. [93] found strong interactions between HMGA1 (high mobility group AT-hook 1) and BRCA1 in sporadic breast carcinoma. In fact, transcriptional binding sites of BRCA1 are edged upstream and downstream by AT-rich sequences which represent preferred binding sites for HMGA1. Moreover, Wan et. al. [67] reported the association of GMEB1 (Glucocorticoid modulatory element binding protein 1 and MCM5 (Minichromosome maintenance deficient 5, cell division cycle 46). In negative counterpart, that EGR1 (Early growth response 1) inversely act towards the BRCA1 expression is evidenced by Cooper [94] and Robson [95]. Substantial facts of TBX3 (T-box 3,) being correlated with BRCA1 has been also reported [96].

Table 7: Association analysis of BTG1, FCGR2B and LCK with transcription factors in terms of regulation pattern.

\begin{tabular}{|c|c|c|c|}
\hline TF & BTG1 & FCGR2B & LCK \\
\hline ETS1 & +0.7230 & +0.6618 & +0.8468 \\
\hline SP110 & +0.7726 & +0.6827 & +0.7928 \\
\hline SP140 & +0.6696 & +0.5598 & +0.7821 \\
\hline HCLS1 & +0.7297 & +0.7877 & +0.8101 \\
\hline TNFAIP3 & +0.5729 & +0.6513 & +0.5316 \\
\hline IFI16 & +0.5869 & +0.6094 & +0.5391 \\
\hline TRIM22 & +0.5860 & +0.6056 & +0.6201 \\
\hline ARNT2 & -0.6084 & -0.2948 & -0.2755 \\
\hline ARNTL & +0.6701 & +0.7616 & +0.5599 \\
\hline ELF1 & +0.6083 & +0.5397 & +0.7234 \\
\hline RBM9 & -0.3579 & -0.3460 & -0.6216 \\
\hline
\end{tabular}

ErbB2/HER2 (HER2/neu, v-erb-b2 erythroblastic leukemia viral oncogene homolog 2, neuro/ glioblastoma derived oncogene homolog) [97-101] is a proto-oncogene located at 17q11.2$\mathrm{q} 12,17 \mathrm{q} 21.1$ and belongs to the epithelial growth factor receptor (EGFR). It codes for a cell membrane surface-bound receptor tyrosine kinase that is expressed abundantly by transcriptional regulation in approximately $20 \%-40 \%$ of breast cancer and it is notably treated as a target gene for therapy. Often it plays a vital role in cell growth, differentiation and metastasis. We found several TFs, like NR2F6, RORC, TEAD3, IRX3, SOX13, PCOLN3, as positively expressed, and MEF2C, ZFP91, MEF2C, ZFP1 as negatively correlated with ErbB2. NR2F6 (Nuclear receptor subfamily 2, group F, member 6) was commented to be coupled with the expression of HER2 [68]. Also in-vitro studies showed that he phosphorylation of the exogenous MEF2C (Myocyte enhancer factor 2C) is dramatically increased by epithelial growth factor (EGF) and thus it refers to its association with controls of ErbB2 expression [102].

\section{Conclusions}

By analyzing tissue-specific gene expression profiles of human and mouse, we produced a list of putative trans-elements and their associated genes. We demonstrated that the use of decay function instead of linear function as regressor is more appropriate for capturing possible 
regulatory relationship. As a measure of the quality of the predicted trans-elements, we focus on the set of transcription factors and genes that share the same gene names in both mouse and human data sets. Our analysis of oncogenes provides further assurance of the quality of the predicted trans-elements. Note that a highly correlated TF-gene pair that is not currently known to bear regulatory relationship may still be a correct trans-element prediction that is yet to be validated. ChIP-chip experiment is designed to test protein-DNA binding, where the binding of a transcription factor to a promoter region of a gene provides necessary but not sufficient evidence for transcription regulation. As a possible further step to confirm the regulatory relationship, the TF-gene pairs and their correlation coefficients constructed here may serve as a source of reference for additional confirmation of ChIP-chip results.

\section{$5 \quad$ Acknowledgements}

This research is supported partially by NSF CCR-0208935, NIH NCRR Research Center at Minority Institutions Grant number 2G12RR1364-06A1 and funding from the University of Texas System. We are also thankful to Dr. Stephen Harris and Dr. Carolina Livi for their valuable comments and suggestions.

\section{References}

[1] J. D. McPherson, M. Marra, L. Hillier, R. H. Waterston, A. Chinwalla, J. Wallis, et al., A physical map of the human genome, Nature, 409, pp. 934-41, 2001.

[2] E. S. Lander, L. M. Linton, B. Birren, C. Nusbaum, M. C. Zody, J. Baldwin, et al., Initial sequencing and analysis of the human genome, Nature, 409, pp. 860-921, 2001.

[3] J. C. Venter, M. D. Adams, E. W. Myers, P. W. Li, R. J. Mural, G. G. Sutton, et al., The sequence of the human genome, Science, 291, pp. 1304-51, 2001.

[4] J. W. Fickett and W. W. Wasserman, Discovery and modeling of transcriptional regulatory regions, Curr Opin Biotechnol, 11, pp. 19-24, 2000.

[5] G. Pavesi, G. Mauri and G. Pesole, In silico representation and discovery of transcription factor binding sites, Brief Bioinform, 5, pp. 217-36, 2004.

[6] L. A. McCue, W. Thompson, C. S. Carmack and C. E. Lawrence, Factors influencing the identification of transcription factor binding sites by cross-species comparison, Genome Res, 12, pp. 1523-32, 2002.

[7] R. Osada, E. Zaslavsky and M. Singh, Comparative analysis of methods for representing and searching for transcription factor binding sites, Bioinformatics, 20, pp. 3516-25, 2004.

[8] S. Sinha and M. Tompa, Discovery of novel transcription factor binding sites by statistical overrepresentation, Nucleic Acids Res, 30, pp. 5549-60, 2002.

[9] S. Sinha and M. Tompa, YMF: A program for discovery of novel transcription factor binding sites by statistical overrepresentation, Nucleic Acids Res, 31, pp. 3586-8, 2003.

[10] A. M. Moses, D. Y. Chiang, D. A. Pollard, V. N. Iyer and M. B. Eisen, MONKEY: identifying conserved transcription-factor binding sites in multiple alignments using a binding site-specific evolutionary model, Genome Biol, 5, pp. R98, 2004. 
[11] S. Aerts, G. Thijs, B. Coessens, M. Staes, Y. Moreau and B. De Moor, Toucan: deciphering the cis-regulatory logic of coregulated genes, Nucleic Acids Res, 31, pp. 1753-64, 2003.

[12] G. Z. Hertz and G. D. Stormo, Identifying DNA and protein patterns with statistically significant alignments of multiple sequences, Bioinformatics, 15, pp. 563-77, 1999.

[13] G. D. Stormo, DNA binding sites: representation and discovery, Bioinformatics, 16, pp. 16-23, 2000.

[14] W. B. Alkema, O. Johansson, J. Lagergren and W. W. Wasserman, MSCAN: identification of functional clusters of transcription factor binding sites, Nucleic Acids Res, 32, pp. W195-8, 2004.

[15] O. Johansson, W. Alkema, W. W. Wasserman and J. Lagergren, Identification of functional clusters of transcription factor binding motifs in genome sequences: the MSCAN algorithm, Bioinformatics, 19 Suppl 1, pp. i169-76, 2003.

[16] J. Zheng, J. Wu and Z. Sun, An approach to identify over-represented cis-elements in related sequences, Nucleic Acids Res, 31, pp. 1995-2005, 2003.

[17] M. Defrance and H. Touzet, Predicting transcription factor binding sites using local over-representation and comparative genomics, BMC Bioinformatics, 7, pp. 396, 2006.

[18] P. E. Boardman, S. G. Oliver and S. J. Hubbard, SiteSeer: Visualisation and analysis of transcription factor binding sites in nucleotide sequences, Nucleic Acids Res, 31, pp. 3572-5, 2003.

[19] A. E. Kel, E. Gossling, I. Reuter, E. Cheremushkin, O. V. Kel-Margoulis and E. Wingender, MATCH: A tool for searching transcription factor binding sites in DNA sequences, Nucleic Acids Res, 31, pp. 3576-9, 2003.

[20] M. C. Frith, M. C. Li and Z. Weng, Cluster-Buster: Finding dense clusters of motifs in DNA sequences, Nucleic Acids Res, 31, pp. 3666-8, 2003.

[21] N. Rajewsky, M. Vergassola, U. Gaul and E. D. Siggia, Computational detection of genomic cis-regulatory modules applied to body patterning in the early Drosophila embryo, BMC Bioinformatics, 3, pp. 30, 2002.

[22] T. Werner, Models for prediction and recognition of eukaryotic promoters, Mamm Genome, 10, pp. 168-75, 1999.

[23] H. J. Bussemaker, H. Li and E. D. Siggia, Regulatory element detection using correlation with expression, Nat Genet, 27, pp. 167-71, 2001.

[24] E. M. Conlon, X. S. Liu, J. D. Lieb and J. S. Liu, Integrating regulatory motif discovery and genome-wide expression analysis, Proc Natl Acad Sci U S A, 100, pp. 3339-44, 2003.

[25] C. T. Workman and G. D. Stormo, ANN-Spec: a method for discovering transcription factor binding sites with improved specificity, Pac Symp Biocomput, pp. 467-78, 2000 .

[26] M. C. Frith, U. Hansen, J. L. Spouge and Z. Weng, Finding functional sequence elements by multiple local alignment, Nucleic Acids Res, 32, pp. 189-200, 2004.

[27] A. V. Favorov, M. S. Gelfand, A. V. Gerasimova, D. A. Ravcheev, A. A. Mironov and V. J. Makeev, A Gibbs sampler for identification of symmetrically structured, spaced 
DNA motifs with improved estimation of the signal length, Bioinformatics, 21, pp. 2240-5, 2005.

[28] K. Ellrott, C. Yang, F. M. Sladek and T. Jiang, Identifying transcription factor binding sites through Markov chain optimization, Bioinformatics, 18 Suppl 2, pp. S100-9, 2002.

[29] W. Ao, J. Gaudet, W. J. Kent, S. Muttumu and S. E. Mango, Environmentally induced foregut remodeling by PHA-4/FoxA and DAF-12/NHR, Science, 305, pp. 1743-6, 2004.

[30] K. A. Frazer, L. Elnitski, D. M. Church, I. Dubchak and R. C. Hardison, Cross-species sequence comparisons: a review of methods and available resources, Genome Res, 13, pp. 1-12, 2003.

[31] S. Batzoglou, L. Pachter, J. P. Mesirov, B. Berger and E. S. Lander, Human and mouse gene structure: comparative analysis and application to exon prediction, Genome Res, 10, pp. 950-8, 2000.

[32] N. Jareborg and R. Durbin, Alfresco--a workbench for comparative genomic sequence analysis, Genome Res, 10, pp. 1148-57, 2000.

[33] A. Ureta-Vidal, L. Ettwiller and E. Birney, Comparative genomics: genome-wide analysis in metazoan eukaryotes, Nat Rev Genet, 4, pp. 251-62, 2003.

[34] B. Lenhard, A. Sandelin, L. Mendoza, P. Engstrom, N. Jareborg and W. W. Wasserman, Identification of conserved regulatory elements by comparative genome analysis, J Biol, 2, pp. 13, 2003.

[35] B. Lenhard, C. Wahlestedt and W. W. Wasserman, GeneLynx mouse: integrated portal to the mouse genome, Genome Res, 13, pp. 1501-4, 2003.

[36] S. R. Eddy, A model of the statistical power of comparative genome sequence analysis, PLoS Biol, 3, pp. e10, 2005.

[37] L. Duret and P. Bucher, Searching for regulatory elements in human noncoding sequences, Curr Opin Struct Biol, 7, pp. 399-406, 1997.

[38] V. X. Jin, A. Rabinovich, S. L. Squazzo, R. Green and P. J. Farnham, A computational genomics approach to identify cis-regulatory modules from chromatin immunoprecipitation microarray data--A case study using E2F1, Genome Res, 2006.

[39] V. X. Jin, G. A. Singer, F. J. Agosto-Perez, S. Liyanarachchi and R. V. Davuluri, Genome-wide analysis of core promoter elements from conserved human and mouse orthologous pairs, BMC Bioinformatics, 7, pp. 114, 2006.

[40] S. Y. Kim and Y. Kim, Genome-wide prediction of transcriptional regulatory elements of human promoters using gene expression and promoter analysis data, BMC Bioinformatics, 7, pp. 330, 2006.

[41] K. Lindblad-Toh, E. S. Lander, J. D. McPherson, R. H. Waterston, J. Rodgers and E. Birney, Progress in sequencing the mouse genome, Genesis, 31, pp. 137-41, 2001.

[42] J. Kawai, A. Shinagawa, K. Shibata, M. Yoshino, M. Itoh, Y. Ishii, et al., Functional annotation of a full-length mouse cDNA collection, Nature, 409, pp. 685-90, 2001.

[43] Y. Okazaki, M. Furuno, T. Kasukawa, J. Adachi, H. Bono, S. Kondo, et al., Analysis of the mouse transcriptome based on functional annotation of 60,770 full-length cDNAs, Nature, 420, pp. 563-73, 2002. 
[44] R. C. Hardison, J. Oeltjen and W. Miller, Long human-mouse sequence alignments reveal novel regulatory elements: a reason to sequence the mouse genome, Genome Res, 7, pp. 959-66, 1997.

[45] R. D. Emes, L. Goodstadt, E. E. Winter and C. P. Ponting, Comparison of the genomes of human and mouse lays the foundation of genome zoology, Hum Mol Genet, 12, pp. 701-9, 2003.

[46] W. W. Wasserman, M. Palumbo, W. Thompson, J. W. Fickett and C. E. Lawrence, Human-mouse genome comparisons to locate regulatory sites, Nat Genet, 26, pp. 2258,2000 .

[47] E. T. Dermitzakis, A. Reymond, R. Lyle, N. Scamuffa, C. Ucla, S. Deutsch, et al., Numerous potentially functional but non-genic conserved sequences on human chromosome 21, Nature, 420, pp. 578-82, 2002.

[48] R. Shyamsundar, Y. H. Kim, J. P. Higgins, K. Montgomery, M. Jorden, A. Sethuraman, et al., A DNA microarray survey of gene expression in normal human tissues, Genome Biol, 6, pp. R22, 2005.

[49] W. Zhang, Q. D. Morris, R. Chang, O. Shai, M. A. Bakowski, N. Mitsakakis, et al., The functional landscape of mouse gene expression, J Biol, 3, pp. 21, 2004.

[50] Entrez Gene http://www.ncbi.nlm.nih.gov/entrez/http://www.ncbi.nlm.nih.gov/entrez/query.fcgi?C $M D=$ search $\& D B=$ gene,

[51] RefSeq www.ncbi.nlm.nih.gov/RefSeq/,

[52] W. W. Wasserman and A. Sandelin, Applied bioinformatics for the identification of regulatory elements, Nat Rev Genet, 5, pp. 276-87, 2004.

[53] V. Matys, E. Fricke, R. Geffers, E. Gossling, M. Haubrock, R. Hehl, et al., TRANSFAC: transcriptional regulation, from patterns to profiles, Nucleic Acids Res, 31, pp. 374-8, 2003.

[54] TRANSFAC-The Transcription Factor Database http://www.generegulation.com/pub/databases.html,

[55] D. S. Chekmenev, C. Haid and A. E. Kel, P-Match: transcription factor binding site search by combining patterns and weight matrices, Nucleic Acids Res, 33, pp. W4327, 2005.

[56] A. Sandelin, W. W. Wasserman and B. Lenhard, ConSite: web-based prediction of regulatory elements using cross-species comparison, Nucleic Acids Res, 32, pp. W249-52, 2004.

[57] Supplementary data link for this page http://www.cs.utsa.edu/ hugelab/supDataTF.html.,

[58] C. Kunsch, S. M. Ruben and C. A. Rosen, Selection of optimal kappa B/Rel DNAbinding motifs: interaction of both subunits of NF-kappa B with DNA is required for transcriptional activation, Mol Cell Biol, 12, pp. 4412-21, 1992.

[59] P. K. Tsantoulis and V. G. Gorgoulis, Involvement of E2F transcription factor family in cancer, Eur J Cancer, 41, pp. 2403-14, 2005.

[60] C. Attwooll, E. Lazzerini Denchi and K. Helin, The E2F family: specific functions and overlapping interests, Embo J, 23, pp. 4709-16, 2004. 
[61] H. Muller, A. P. Bracken, R. Vernell, M. C. Moroni, F. Christians, E. Grassilli, et al., E2Fs regulate the expression of genes involved in differentiation, development, proliferation, and apoptosis, Genes Dev, 15, pp. 267-85, 2001.

[62] G. J. Lindeman, L. Dagnino, S. Gaubatz, Y. Xu, R. T. Bronson, H. B. Warren, et al., A specific, nonproliferative role for E2F-5 in choroid plexus function revealed by gene targeting, Genes Dev, 12, pp. 1092-8, 1998.

[63] B. Czermin, R. Melfi, D. McCabe, V. Seitz, A. Imhof and V. Pirrotta, Drosophila enhancer of Zeste/ESC complexes have a histone H3 methyltransferase activity that marks chromosomal Polycomb sites, Cell, 111, pp. 185-96, 2002.

[64] A. Kuzmichev, K. Nishioka, H. Erdjument-Bromage, P. Tempst and D. Reinberg, Histone methyltransferase activity associated with a human multiprotein complex containing the Enhancer of Zeste protein, Genes Dev, 16, pp. 2893-905, 2002.

[65] A. P. Bracken, D. Pasini, M. Capra, E. Prosperini, E. Colli and K. Helin, EZH2 is downstream of the pRB-E2F pathway, essential for proliferation and amplified in cancer, Embo J, 22, pp. 5323-35, 2003.

[66] R. Kurzrock, H. M. Kantarjian, B. J. Druker and M. Talpaz, Philadelphia chromosome-positive leukemias: from basic mechanisms to molecular therapeutics, Ann Intern Med, 138, pp. 819-30, 2003.

[67] D. Wan, Y. Gong, W. Qin, P. Zhang, J. Li, L. Wei, et al., Large-scale cDNA transfection screening for genes related to cancer development and progression, Proc Natl Acad Sci U S A, 101, pp. 15724-9, 2004.

[68] M. A. Gieseg, T. Cody, M. Z. Man, S. J. Madore, M. A. Rubin and E. P. Kaldjian, Expression profiling of human renal carcinomas with functional taxonomic analysis, BMC Bioinformatics, 3, pp. 26, 2002.

[69] X. S. Puente, G. Velasco, A. Gutierrez-Fernandez, J. Bertranpetit, M. C. King and C. Lopez-Otin, Comparative analysis of cancer genes in the human and chimpanzee genomes, BMC Genomics, 7, pp. 15, 2006.

[70] M. Stanulla, H. J. Schunemann, S. Thandla, M. L. Brecher and P. D. Aplan, Pseudorearrangement of the MLL gene at chromosome 11q23: a cautionary note on genotype analysis of leukaemia patients, Mol Pathol, 51, pp. 85-9, 1998.

[71] L. W. Deng, I. Chiu and J. L. Strominger, MLL 5 protein forms intranuclear foci, and overexpression inhibits cell cycle progression, Proc Natl Acad Sci U S A, 101, pp. 757-62, 2004.

[72] S. Yamamoto, M. Nishi, K. Taniguchi, M. Imayoshi, Y. Ogata, M. Iwanaga, et al., Partial tandem duplication of MLL gene in acute myeloid leukemia with translocation (11;17)(q23;q12-21), Am J Hematol, 80, pp. 46-9, 2005.

[73] J. L. Best, C. A. Amezcua, B. Mayr, L. Flechner, C. M. Murawsky, B. Emerson, et al., Identification of small-molecule antagonists that inhibit an activator: coactivator interaction, Proc Natl Acad Sci U S A, 101, pp. 17622-7, 2004.

[74] D. Wiederschain, H. Kawai, J. Gu, A. Shilatifard and Z. M. Yuan, Molecular basis of p53 functional inactivation by the leukemic protein MLL-ELL, Mol Cell Biol, 23, pp. 4230-46, 2003.

[75] T. Waldmann, I. Scholten, F. Kappes, H. G. Hu and R. Knippers, The DEK protein-an abundant and ubiquitous constituent of mammalian chromatin, Gene, 343, pp. 1-9, 2004. 
[76] T. Waldmann, M. Baack, N. Richter and C. Gruss, Structure-specific binding of the proto-oncogene protein DEK to DNA, Nucleic Acids Res, 31, pp. 7003-10, 2003.

[77] D. Y. Lin, H. I. Fang, A. H. Ma, Y. S. Huang, Y. S. Pu, G. Jenster, et al., Negative modulation of androgen receptor transcriptional activity by Daxx, Mol Cell Biol, 24, pp. 10529-41, 2004.

[78] K. Metcalfe, H. T. Lynch, P. Ghadirian, N. Tung, I. Olivotto, E. Warner, et al., Contralateral breast cancer in BRCA1 and BRCA2 mutation carriers, J Clin Oncol, 22, pp. 2328-35, 2004.

[79] W. D. Foulkes, K. Metcalfe, P. Sun, W. M. Hanna, H. T. Lynch, P. Ghadirian, et al., Estrogen receptor status in BRCA1- and BRCA2-related breast cancer: the influence of age, grade, and histological type, Clin Cancer Res, 10, pp. 2029-34, 2004.

[80] A. Antoniou, P. D. Pharoah, S. Narod, H. A. Risch, J. E. Eyfjord, J. L. Hopper, et al., Average risks of breast and ovarian cancer associated with BRCA1 or BRCA2 mutations detected in case Series unselected for family history: a combined analysis of 22 studies, Am J Hum Genet, 72, pp. 1117-30, 2003.

[81] G. L. Barnett and C. A. Friedrich, Recent developments in ovarian cancer genetics, Curr Opin Obstet Gynecol, 16, pp. 79-85, 2004.

[82] D. C. Daniel, Highlight: BRCA1 and BRCA2 proteins in breast cancer, Microsc Res Tech, 59, pp. 68-83, 2002.

[83] S. L. Ding, L. F. Sheu, J. C. Yu, T. L. Yang, B. F. Chen, F. J. Leu, et al., Abnormality of the DNA double-strand-break checkpoint/repair genes, ATM, BRCA1 and TP53, in breast cancer is related to tumour grade, Br J Cancer, 90, pp. 1995-2001, 2004.

[84] A. Liede, B. Y. Karlan and S. A. Narod, Cancer risks for male carriers of germline mutations in BRCA1 or BRCA2: a review of the literature, J Clin Oncol, 22, pp. 73542, 2004.

[85] S. N. Powell and L. A. Kachnic, Roles of BRCA1 and BRCA2 in homologous recombination, DNA replication fidelity and the cellular response to ionizing radiation, Oncogene, 22, pp. 5784-91, 2003.

[86] R. Scully and N. Puget, BRCA1 and BRCA2 in hereditary breast cancer, Biochimie, 84, pp. 95-102, 2002.

[87] A. A. Tutt A, The relationship between the roles of BRCA genes in DNA repair and cancer predisposition, Trends Mol Med, 8, pp. 571-6, 2002.

[88] A. R. Venkitaraman, Cancer susceptibility and the functions of BRCA1 and BRCA2, Cell, 108, pp. 171-82, 2002.

[89] B. N. Nadeau G, Moisan A, Lemieux KM, Cayanan C, Monteiro AN, Gaudreau L, BRCA1 can stimulate gene transcription by a unique mechanism. EMBO Rep. 2000 Sep 15; 1(3): 260-265., EMBO Rep., 1, pp. 260-265, 2000.

[90] P. S. Warrenfeltz S, Datta S, Kraemer ET, Benigno B, McDonald JF, Gene expression profiling of epithelial ovarian tumors correlated with malignant potential., Mol Cancer, 3, 2004.

[91] L. Hennighausen, Mouse models for breast cancer, Breast Cancer Res, 2, pp. 2-7, 2000 .

[92] J. Jimeno, M. Aracil and J. C. Tercero, Adding pharmacogenomics to the development of new marine-derived anticancer agents, J Transl Med, 4, pp. 3, 2006. 
[93] B. S. Baldassarre G, Belletti B, Thakur S, Pentimalli F, Trapasso F, Fedele M, Pierantoni G, Croce CM, Fusco A., Negative Regulation of BRCA1 Gene Expression by HMGA1 Proteins Accounts for the Reduced BRCA1 Protein Levels in Sporadic Breast Carcinoma., Mol Cell Biol., Apr; 23, pp. 2225-2238, 2003.

[94] C. S. Cooper, Applications of microarray technology in breast cancer research, Breast Cancer Res, 3, pp. 158-75, 2001.

[95] T. Robson and D. G. Hirst, Transcriptional Targeting in Cancer Gene Therapy, J Biomed Biotechnol, 2003, pp. 110-137, 2003.

[96] A. L. Welm, AACR Special Conference: Advances in Breast Cancer Research-Genetics, Biology, and Clinical Implications, Huntington Beach, California, USA, 812 October 2003, Breast Cancer Res, 6, pp. E6, 2004.

[97] J. Bange, E. Zwick and A. Ullrich, Molecular targets for breast cancer therapy and prevention, Nat Med, 7, pp. 548-52, 2001.

[98] T. Kute, C. M. Lack, M. Willingham, B. Bishwokama, H. Williams, K. Barrett, et al., Development of Herceptin resistance in breast cancer cells, Cytometry A, 57, pp. 8693, 2004.

[99] S. Menard, S. M. Pupa, M. Campiglio and E. Tagliabue, Biologic and therapeutic role of HER2 in cancer, Oncogene, 22, pp. 6570-8, 2003.

[100] R. Nahta and F. J. Esteva, HER-2-targeted therapy: lessons learned and future directions, Clin Cancer Res, 9, pp. 5078-84, 2003.

[101] D. Yu and M. C. Hung, Overexpression of ErbB2 in cancer and ErbB2-targeting strategies, Oncogene, 19, pp. 6115-21, 2000.

[102] D.-R. E. Esparís-Ogando A, Montero JC, Yuste L, Crespo P, Pandiella A., Erk5 Participates in Neuregulin Signal Transduction and Is Constitutively Active in Breast Cancer Cells Overexpressing ErbB2., Mol Cell Biol., Jan; 22, pp. 270-285., 2002.

\section{Additional files}

\section{Additional file 1- Tf-gene.bmp}

It contains the figure used in the manuscript

\section{Additional file 2- Tf-gene1.bmp}

It contains the figure used in the manuscript 